\title{
Development of an Efficient In vitro Regeneration Protocol for Chrysanthemum (Chrysanthemum morifolium Ramat)
}

\author{
Jebunnesa Chowdhury ${ }^{1}$, M.I. Hoque and R.H. Sarker* \\ Plant Breeding and Biotechnology Laboratory, Department of Botany, University of Dhaka, \\ Dhaka-1000, Bangladesh
}

Keywords: Organogenesis, In vitro regeneration, Chrysanthemum

\begin{abstract}
An efficient and rapid in vitro regeneration protocol was developed for chrysanthemum (Chrysanthemum morifolium Ramat) using two local varieties of Bangladesh namely, BARI Chrysanthemum-2 (BARI Chry-2) and local yellow (Y). MS medium supplemented with nine different concentrations and combinations of BAP and IAA was employed to optimize regeneration protocol using young in vitro derived leaf explants. Direct organogenesis was observed from the leaf explants on MS medium supplemented with $0.5 \mathrm{mg} / \mathrm{BAP}$ and $2.0 \mathrm{mg} / \mathrm{IAA}$ (T6) for both the varieties. This treatment (T6) induced shoot buds directly on the adaxial surface of the leaf providing the highest regeneration percentage ( $90 \%$ for BARI Chry-2 and $94.73 \%$ for Y), the highest number of shoot/explant (7.6 for BARI Chry-2 and 8.6 for Y) and maximum length of the shoot after six weeks (3 $\mathrm{cm}$ for BARI Chry-2 and $2.9 \mathrm{~cm}$ for $\mathrm{Y}$ ) of culture. Explants with initially regenerated shoots were subculture on hormone free MS medium for shoot elongation after 4 weeks of their inoculation. During elongation of shoots, $90-95 \%$ of the regenerated shoots produced roots spontaneously in hormone free MS medium within 7-8 weeks of their inoculation. Rooted plantlets were transplanted to the field following hardening where $100 \%$ plantlets were survived and produced flower without any variation.
\end{abstract}

\section{Introduction}

Chrysanthemum (Chrysanthemum morifolium Ramat) is considered as one of the most popular cut flowers as well as pot plants worldwide due to its assorted floral types and colors. It occupies the second place on the world sales list, following rose (Miler and Jędrzejczyk 2018). As the world flower market is growing, the demands for new varieties have become a major issue in the flower industry. Despite a great number of cultivars

*Author for correspondence: <rhsarker@du.ac.bd>. ${ }^{1}$ This article is a part of the research findings of the first author (JC) for her higher studies leading to Ph.D. Present address: Department of Mathematics and Natural Sciences, BRAC University, 66 Mohakhali C/A, Dhaka-1212, Bangladesh. 
available, customers and breeders are constantly searching for new phenotypes for commercial utilization. (Tymoszuk and Kulus 2020)

In vitro adventitious shoot regeneration is the most used technique for by various factors, including interactions among plant growth regulators, dark period of creating new cultivars of chrysanthemum, both in case of mutation breeding as well as in genetic transformation (Lim et al. 2012). However, in vitro shoot regeneration of chrysanthemum is affected the culture condition, gelling agents of the medium, ethylene inhibitors, explant type, and the plant genotype. (Lim et al. 2012, Naing et al. 2014, Samala et al. 2017)

Effective in vitro regeneration depends on two important factors i.e., the concentrations of auxins and cytokinins for their organogenic/embryogenic responses due to a broad and effective interventions in the cell cycle regulation and cell division. For genetic modification, particular plant cultivars with high regeneration ability are generally required. Therefore, the processes for the induction of embryogenic calli and consequent regeneration of plantlets are significantly dependent on the genotype of the plant material (Huang et al. 2018).

In a developing country like Bangladesh, floriculture is gaining popularity as the use of flowers has increased enormously in different social and official occasions. Uncommon flower color, size and shape of flowers always fascinate flower lovers, thus creating high demand in the market. A limited number of chrysanthemum varieties are available in Bangladesh and this plant can be grown only in winter. Several studies revealed that the production of regenerated plants through direct or indirect organogenesis and somatic embryogenesis are not only applicable to produce large number of plants, but these are also possible methods in creating genetic variability in chrysanthemum species (Miler and Malgorzata 2014, Lema-Rumińska and Mellem 2017, Huang et al. 2018). Thus, the resulting plants can be developed as desired somaclones (Zalewska et al. 2011).

The aim of the study was to develop a rapid and efficient in vitro regeneration as well as multiplication protocols for local varieties of Chrysanthemum morifolium Ramat. It was carried out as a part of the investigation in developing novel mutants from gamma irradiated in vitro grown plants of local varieties. The effects of different plant growth regulators (PGRs) as supplements of MS medium on shoot induction and subsequent root formation was investigated. To our knowledge, there is no report available on invitro regeneration protocol for chrysanthemum varieties available in Bangladesh using in-vitro grown leaves, although there are few reports available on regeneration from nodal segments and internodes from imported varieties of chrysanthemum (Yesmin et al. 2014). Therefore, based on the above-mentioned information experiments were conducted to develop a rapid and efficient in vitro regeneration protocol for the local varieties of chrysanthemum through direct organogenesis. 


\section{Materials and Methods}

Two different varieties of chrysanthemum, namely BARI Chrysanthemum-2 (BARI Chry-2) having white flower and a locally available imported variety (Y) having yellow flowers were used for this study. BARI Chry-2 was collected from Ornamental and Floriculture Division of the Horticulture Research Center (HRC), Bangladesh Agricultural Research Institute (BARI), Joydebpur, Gazipur, Bangladesh and yellow variety (Y) was collected from Krishibid Upokoron Nursery, Agargaon, Dhaka. Both the mother plants were maintained in the Botanical Garden of the Department of Botany, University of Dhaka.

Shoot tips were excised from garden grown mother plants and washed under running tap water for 30 minutes. Then they were treated with a locally available mild detergent in water for 15 minutes and were washed thoroughly under tap water followed by 3-4 times washing with distilled water. Further steps of sterilization of explants were carried out in a laminar air flow cabinet where previously clean explants were immersed in $0.8 \%(\mathrm{v} N)$ sodium hypochlorite solution for 10 minutes followed by 34 times rinsing with sterile distilled water. During the rainy season an extra step was introduced to minimize contamination rate of the explants by immersing them in $70 \%$ ethanol for 1 minute followed by 3-4 times wishing with distilled water. Sterilized shoot tips were then cultured on hormone free MS medium for explant collection and repeated subculture was performed at two weeks interval to ensure supply of adequate leaf explants. Two weeks old shoot tip cultured on MS medium were the source of young leaves ( $4^{\text {th }}$ and $5^{\text {th }}$ position). Leaf explants with midrib of about $0.5-1.0 \mathrm{~cm}$ long was inoculated in different hormonal supplemented regeneration media to examine the variable regeneration responses.

These leaf explants were cultured on MS medium supplemented with different concentrations and combinations of BAP $(0.5-1.0 \mathrm{mg} \Lambda)$ and IAA $(0.5-2.0 \mathrm{mg} \Lambda)$ to study their effects on organogenesis towards the development of shoots and plantlets. These hormonal supplements in MS medium were used to formulate nine different treatment combinations (T1-T9) (Table 1). Responsive leaf explants with different stages of organogenesis were cut into small pieces during subculture to fresh medium containing the same hormonal supplements for further proliferation and development of shoots. Subculture was performed regularly at an interval of two weeks for maintenance of cultures avoiding contamination. Shoot proliferation, multiplication and shoot elongation was carried out on MS medium (hormone free) following multiple shoot induction in 4-5 weeks old culture.

Following sufficient development of shoots after maintaining 4-5 weeks of culture, $1.5-2.0 \mathrm{~cm}$ long shoots were separated and cultured on hormone free MS medium for 1-2 weeks to get healthy and effective roots from these shoots. MS medium containing various treatments (Table 1) used for these experiments contained 3\% sucrose and $0.8 \%$ agar. The $\mathrm{pH}$ of the medium was adjusted to 5.8 before autoclaving at $121^{\circ} \mathrm{C}$ for 15 
minutes. All the cultures were maintained at $22-24^{\circ} \mathrm{C}$ under a $16 \mathrm{hrs}$ photoperiod with a light intensity of $72 \mu \mathrm{mol} \mathrm{m} \mathrm{m}^{2} / \mathrm{s}$.

The plantlets with sufficient root system were taken out from the culture vessels and the roots were washed under running tap water. The plantlets were then transplanted to small pots containing soil, sand, and organic fertilizer in the ratio $1: 2: 1$. Pots were then covered with transparent perforated polythene bags for acclimatization. To reduce sudden shock, the pots were kept in growth room for two weeks, of which polythene covers were maintained for the first week and without cover for the second week. These plantlets were exposed to natural environment for 2-8 hours daily and again placed in growth room for another week. Three weeks after transplantation, when the regenerated plants were fully established in the small pots, they were then transferred to field condition. All the plants survived maintained until their flowering.

The experiments were carried out in a completely randomized design (CRD) with two varieties and nine treatments (Table 1) of PGRs supplemented MS medium using leaf explant. There were 3 replications for each variety and the treatment combination while each replication consisted of 10 explants in a conical flask. Regeneration response parameters were observed and recorded for five-seven weeks of culture. Two-way analysis of variance (ANOVA) and a Tukey's multiple comparison test were performed to compare various types of regeneration responses for nine treatments. The required statistical analysis was carried out using "Prism GraphPad 8.0" software.

\section{Results and Discussion}

Several successful in vitro regeneration studies for Chrysanthemum morifolium have shown a clear relationship between plant varieties and the various combinations of plant growth regulators (PGRs) towards different explants. The effects of various combinations of PGRs in MS medium on organogenesis using leaf explants with midrib was tested following the development of shoots (Table 1). Analysis of variance for various responses of regeneration under nine treatments (T1-T9) in two varieties is shown in Figs 1-3 and Table 1. Statistical analysis showed significant difference in the percentages of regeneration responses, mean number of shoot/explant as well as in the mean shoot length for the nine treatments in both tested varieties. Interaction between hormonal combinations in MS medium (treatments) and the varieties were also found significant.

In vitro regeneration of chrysanthemum was found to be highly influenced by the interaction of PGRs, plant genotype and explants type (Lim et al. 2012, Teixeira et al. 2015). Most of the studies revealed direct/indirect organogenesis/embryogenesis of $C$. morifolium in MS medium using different concentrations of auxins (NAA, IAA, 2, 4-D) along with that of cytokinins (BAP, BA and TDZ) (Lim et al. 2012, Huang et al. 2018, Kazeroonian et al. 2018). Present study revealed that the addition of (0.5 $\mathrm{mg} /$ ) IAA in MS media induced regeneration responses in leaf explants and a significant increase in regeneration percentage were recorded (from 37.5 to $76 \%$ for yellow flowered variety and 
35.7 to $70 \%$ for BARI Chry-2 variety) up to the application of $1 \mathrm{mg} /$ IAA. But higher concentrations of auxin, like $2 \mathrm{mg} /$ IAA in MS medium showed a negative effect on regeneration percentages for both the varieties $(60.3 \%$ for yellow and $48.3 \%$ for BARI Chry-2) (Fig. 1). Nevertheless, these results were found to be identical with previous studies using NAA (Xu et al. 2012, Naing et al. 2014, Nasri et al. 2018,).

Table 1. Tukey's multiple comparisons test for regeneration response for two varieties of chrysanthemum in nine treatments.

\begin{tabular}{|c|c|c|c|c|}
\hline Treatment & Mean Diff. & $\begin{array}{l}95.00 \% \text { CI of } \\
\text { diff. }\end{array}$ & Summary & $\begin{array}{l}\text { Adjusted } \\
\text { P Value }\end{array}$ \\
\hline $\mathrm{T} 1=\mathrm{MS}+0.5 \mathrm{mg} / \mathrm{IAA}$ & 1.833 & -2.674 to 6.341 & Ns & 0.9825 \\
\hline $\mathrm{T} 2=\mathrm{MS}+1 \mathrm{mg} \lambda$ IAA & 6 & 1.493 to 10.51 & ** & 0.0017 \\
\hline $\mathrm{T} 3=\mathrm{MS}+2 \mathrm{mg} \not \mathrm{IAA}$ & 12 & 7.493 to 16.51 & $* * *$ & $\varangle 0.0001$ \\
\hline $\mathrm{T} 4=\mathrm{MS}+0.5 \mathrm{mg} / \mathrm{IAA}+0.5 \mathrm{mg} / \mathrm{BAP}$ & -0.6667 & -5.174 to 3.841 & Ns & $>0.9999$ \\
\hline $\mathrm{T} 5=\mathrm{MS}+1 \mathrm{mg} / \mathrm{IAA}+0.5 \mathrm{mg} / \mathrm{BAP}$ & 0 & -4.507 to 4.507 & Ns & $>0.9999$ \\
\hline $\mathrm{T} 6=\mathrm{MS}+2 \mathrm{mg} \not \mathrm{IAA}+0.5 \mathrm{mg} \not \mathrm{BAP}$ & 4.737 & 0.2295 to 9.244 & * & 0.0311 \\
\hline $\mathrm{T} 7=\mathrm{MS}+0.5 \mathrm{mg} \lambda \mathrm{IAA}+1.0 \mathrm{mg} \lambda \mathrm{BAP}$ & 0 & -4.507 to 4.507 & ns & $>0.9999$ \\
\hline $\mathrm{T} 8=\mathrm{MS}+1 \mathrm{mg} / \mathrm{IAA}+1.0 \mathrm{mg} \wedge \mathrm{BAP}$ & -6.25 & -10.76 to -1.743 & $* * *$ & 0.0009 \\
\hline $\mathrm{T} 9=\mathrm{MS}+2 \mathrm{mg} \not \mathrm{IAA}+1.0 \mathrm{mg} \lambda \mathrm{BAP}$ & 3.667 & -0.8407 to 8.174 & ns & 0.2295 \\
\hline
\end{tabular}

Ns, non-significant; *** highly significant and * significant at $\mathrm{P} \leq 0.01$.

Interesting results were found when a combination of auxin and cytokinin were used. Addition of $0.5 \mathrm{mg} / \mathrm{BAP}$ to $0.5 \mathrm{mg} / \mathrm{IAA}+\mathrm{MS}$ medium increased regeneration in two-fold, but further raised level of BAP $(1 \mathrm{mg} \Lambda)$ showed no significant change in regeneration response. Again, high concentration of IAA $(2 \mathrm{mg} /)$ along with low BAP $(0.5 \mathrm{mg} /)$ in MS medium exhibited dramatic increase in regeneration response for both the both varieties $(94.73 \%$ for yellow and $90 \%$ for BARI Chry-2). While addition of more cytokinin (MS + $2.0 \mathrm{mg} / \mathrm{IAA}+1.0 \mathrm{mg} / \mathrm{BAP}$ ) dropped (74\% for yellow and $70.33 \%$ for BARI Chry-2) the regeneration rate. These findings indicated that lower concentrations of auxin (MS+1.0 mg/ IAA $+1.0 \mathrm{mg} / \mathrm{BAP}$ ) showed an increase in regenerations responses ( $81.25 \%$ for yellow and $87.5 \%$ for white variety) for both the varieties (Fig. 1). Similar findings were obtained in several studies using the identical groups of hormones $(\mathrm{Xu}$ et al. 2012, Naing et al. 2014, Kazeroonian et al. 2018).

Addition of cytokinin in the regeneration medium generally increases shoot number per explant. Several previous reports have confirmed that BAP accelerates the development of the shoot buds as well as enhancing the shoot primordial development in chrysanthemum and in other plants (Lee et al. 1997, Yesmin et al. 2014, Kazeroonian et al. 2018). Among the nine treatments tested T6 produced highest mean number of 
shoot/explant 8.67 and 7.67 for $\mathrm{Y}$ and BARI Chry-2 variety, respectively. Minimum shoot/explant (mean number) were produced from T1, T2 and T3 (2.33-2.67) (Fig. 2).

Highest mean shoot length for both varieties were found to be approximately $3 \mathrm{~cm}$ after six weeks of culture initiated from the treatment T6 (MS+ $2 \mathrm{mg} / \mathrm{IAA}+0.5 \mathrm{mg} / \mathrm{BAP}$ ) and minimum mean shoot length approximately $1.6 \mathrm{~cm}$ were found in case of treatments $\mathrm{T} 1$ and $\mathrm{T} 3$ derived shoots. Treatment T7 (MS + $0.5 \mathrm{mg} / \mathrm{IAA}+1.0 \mathrm{mg} / \mathrm{BAP}$ ) and T8 (MS + $2.0 \mathrm{mg} / \mathrm{IAA}+1.0 \mathrm{mg} / \mathrm{BAP}$ ) produced approximately 5 shoots/explant (mean number) and mean shoot length was 2.2-2.0 cm for both varieties (Figs 2-3).

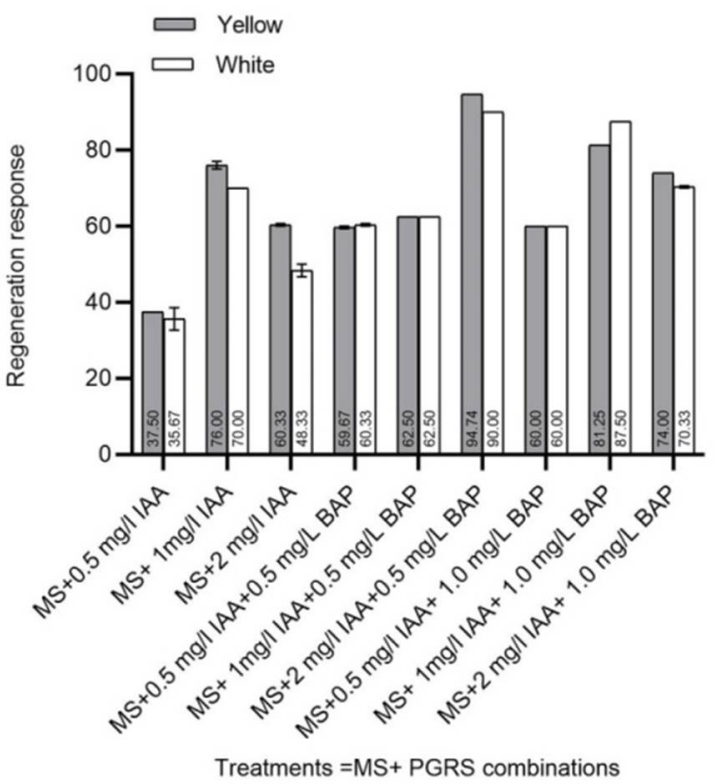

Fig. 1. Effects of different treatments for regeneration responses in two varieties using leaf explants.

Data are mean of three replicates with bars representing SEM.

Considering all investigating factors of regeneration, T6 treatment was found to be the best for the varieties (Figs 1-3). Almost an identical treatment containing MS medium supplemented with $0.6 \mathrm{mg} / \mathrm{BAP}$ and $2.0 \mathrm{mg} \Lambda$ IAA was also reported to be effective for leaf, internode, and single node culture (Zalewska et al. 2011, Miler and Malgorzata 2014, Tymoszuk and Kulus 2020).

Moreover, during this study significant effects were found between variety and treatment (media with PGRs) on regeneration, shoot/explant and shoot length producing capacity of the two tested chrysanthemum varieties using the leaf explants. Following ANOVA and Tukey's multiple comparisons test deduced significant differences in the percentage of regeneration response towards T2, T3, T6 and T8 treatment, whereas T1, T4, T5, T7 and T9 showed no significant differences between the varieties (Table 1). So different variety may have different response towards the same treatment for the same explant type. 


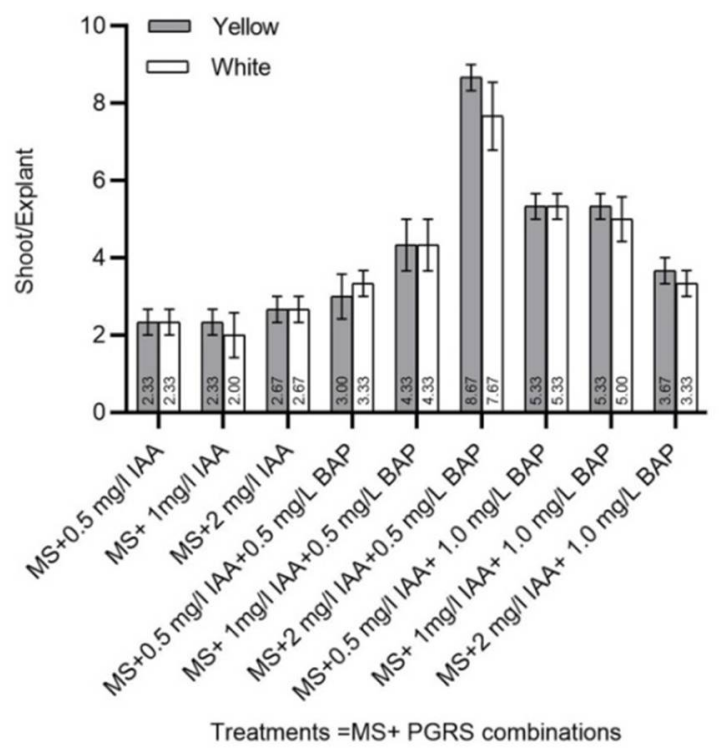

Fig. 2. Effects of different treatments on number of shoot/explant on leaf explant of two varieties. Data are mean of three replicates with bars representing SEM.

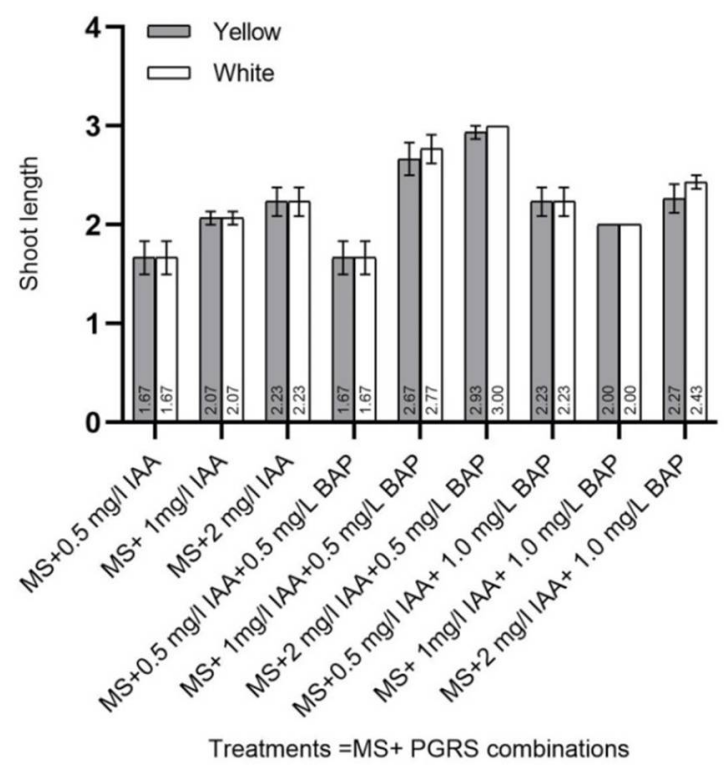

Fig. 3. Effects of different treatments on shoot lengths of the regenerated shoots from leaf explants in the two varieties after six weeks. Data are mean of three replicates with bars representing SEM.

To study the process of organogenesis leaf explants containing midrib were inoculated in T6 (MS + IAA $2.0 \mathrm{mg} \Lambda$ + BAP $0.5 \mathrm{mg} \Lambda$ ) treatment. The inoculated explants 
became enlarged and curved within 7-10 days of culture (Fig. 4A) and adventitious shoot buds were developed by 2 weeks of culture (Fig. 4B). Clusters of multiple shoots with well-developed leaves were formed by the end of 4 weeks of culture (Fig. 4C). Adventitious shoot bud induction and developmental sequence of shoot primordia has been illustrated for BARI Chry-2 variety in Fig. 4.
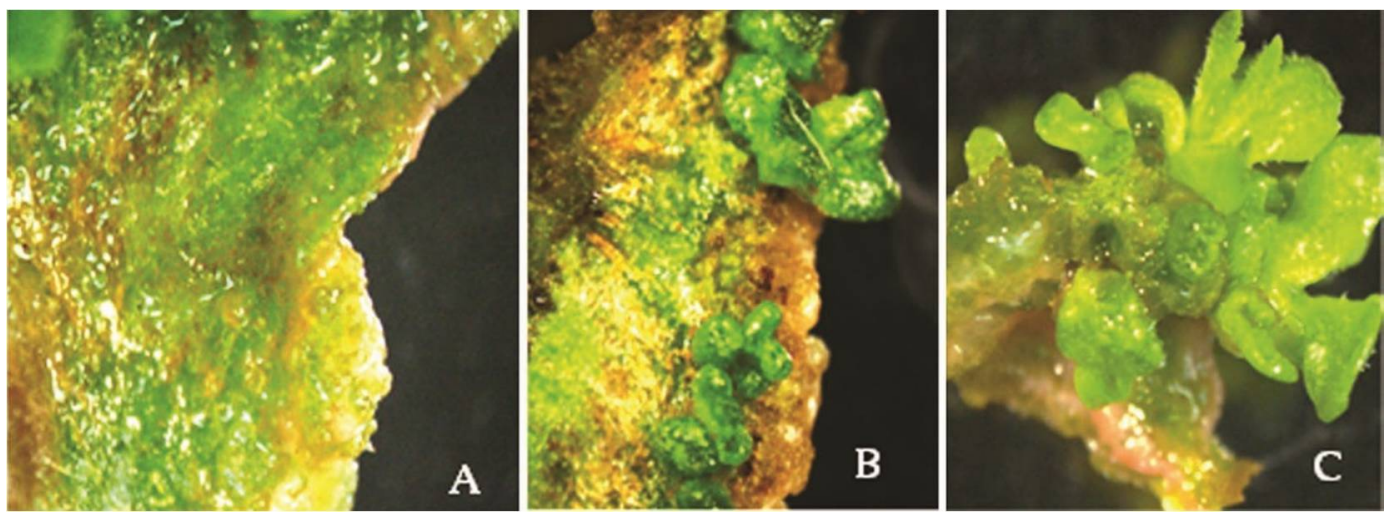

Fig. 4. Adventitious shoot bud initiation and multiple shoot induction in BARI Chry-2 variety. A) Enlarged and curved leaf explant after 1 week of culture. B) Early stages of apical shoot and globular shape bud formation after 2 weeks of culture. C) Formation of multiple shoots after 4 weeks of culture.

Current study revealed that MS medium supplemented with low concentration of BAP and high concentration of IAA (T6) were optimum for direct organogenesis providing best regeneration responses. $\mathrm{Xu}$ et al. (2012) found low concentration of BA and high concentration of NAA were most effective for the formation of calli and somatic embryogenesis. However, this result was different from many other studies showing importance on embryonic callus induction through 2,4-D along with BAP or other cytokinins (Huang et al. 2018, Jaramillo et al. 2008). Aforementioned findings showed that lower concentration of NAA played a key role in the process of chrysanthemum regeneration which was not similar to the results of the present study. This may be due to the use of different explant and species of chrysanthemum used in this investigation $(\mathrm{Xu}$ et al. 2012).

The present findings revealed that subsequent subculture of the explants after 4 weeks in a hormone free MS medium enhanced the production of multiple shoots (Fig. 5A). Therefore, MS medium (hormone free) were used for further shoot proliferation and shoot elongation for 5-6 weeks till the regenerated shoots achieved the optimum (3.0-3.5 $\mathrm{cm}$ ) length (Fig. 5C). Almost similar response was found for both the varieties using T6 treatment in regenerating shoots. Several reports also suggested that the development of somatic embryo and plant regeneration can be achieved through the application of lower 
concentration of auxin or auxin free MS medium (Jaramillo et al. 2008, Xu et al. 2012, Huang et al. 2018).

During shoot elongation and multiplication spontaneous rooting was observed when consequent subcultures were done in hormone free MS medium (Fig. $5 \mathrm{D}$ and E). In both the varieties more than 90-95\% shoots were found to produce healthy roots within 6 to 7 weeks of culture. These findings were identical to the other reports for different chrysanthemum varieties (Jaramillo et al. 2008, Naing et al. 2014, Kazeroonian et al. 2018). Superior plant growth and rooting was observed on a hormone free MS medium solidified with Gelrite. Rooting occurred spontaneously in most of the cases without the application of any exogenous growth regulator in the culture medium (Naing et al. 2014). However, several study showed healthy root induction in full, or half strength of MS medium supplemented with lower concentration of auxin (IBA/AAANAA) (Sarker and Ismat 2001, Waseem et al. 2011, Yesmin et al. 2014, Miler and Kulus 2018).
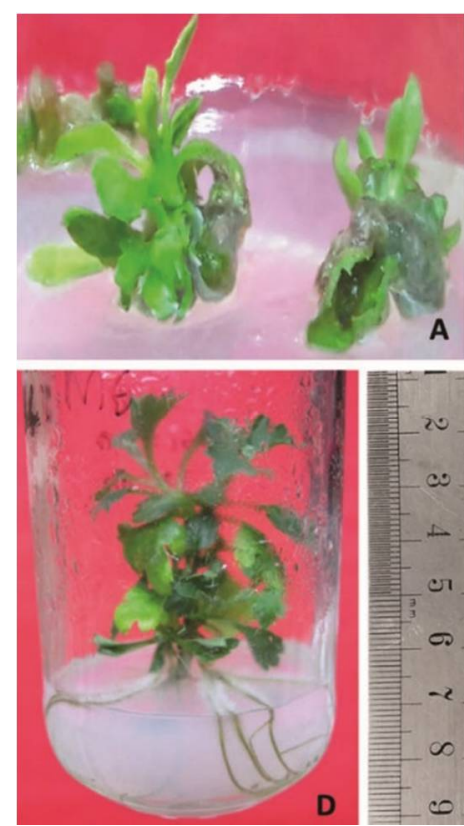
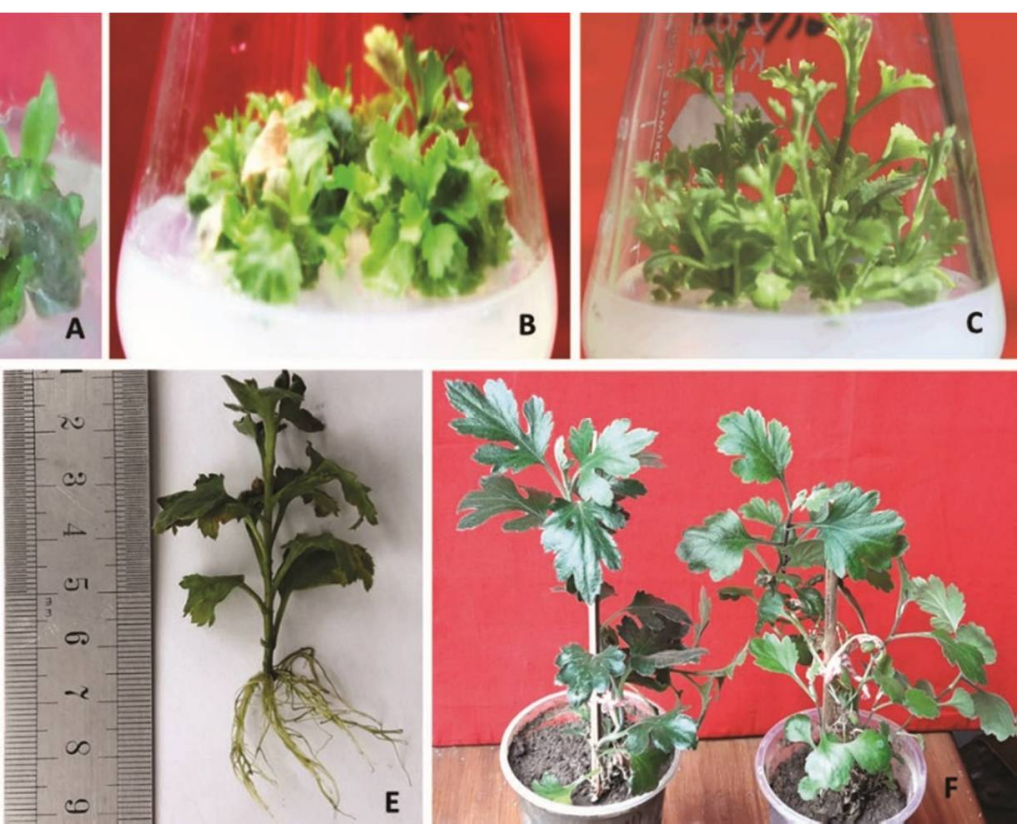

Fig. 5. Development of plantlets from leaf explants and hardening of plantlets of BARI Chry-2: (A) Shoot induction after 4 weeks of culture in T6 treatment, (B-C) Shoot multiplication and elongation after 5-6 weeks in hormone free MS medium, (D) Spontaneous rooting of the regenerated shoot during elongation and multiplication after 6-7 weeks of culture, (E) Healthy rooted plantlet ready to transfer in soil after 8 weeks, (F) Acclimatized healthy plants ready to transplant in the field.

All excised elongated shoots developed into complete rooted plantlets within 2 months following proper transplantation. The plantlets with sufficient root system were taken out from the culture vessels after 7-8 weeks of culture and transplanted to small 
pots containing soil, sand, and organic fertilizer in the ratio 1: 2: 1 (Fig. 5F) and were allowed to acclimatized adequately. Three weeks after transplantation, when the regenerated plants were fully established in the small pots, they were then transferred to field. All the survived plants were maintained there until flowering occurred and the flowers showed normal morphology without any variation.

Finally, it can be concluded that the current study established an efficient and rapid regeneration protocol for the local varieties of chrysanthemum. Best response towards organogenesis was observed when leaf explants were cultured on MS medium supplemented with $0.5 \mathrm{mg} / \mathrm{BAP}$ and $2.0 \mathrm{mg} / \mathrm{IAA}$ (T6) for both the varieties. Following shoot induction regenerated shoots were elongated and multiplied in PGRs free MS medium. During their elongation regenerated shoots produced effective roots simultaneously in hormone free MS medium, thus the protocol can be considered as a unique and rapid regarding micropropagation. This developed protocol can be utilized for the large-scale rapid propagation of local chrysanthemum varieties. Moreover, this in vitro regeneration protocol can be used in developing plantlets following mutagenesis using gamma radiation towards the creation of variation for both the varieties of chrysanthemum.

\section{Acknowledgements}

This study was financially supported by Bangabandhu Fellowship Trust, Bangladesh which is gratefully acknowledged.

\section{References}

Huang M, Ma X, Zhong Y, Hu Q, Fu M and Han Y (2018) Callus induction and plant regeneration of Spirodela polyrhiza. Plant Cell, Tissue and Organ Cult. 135(3): 445-453. https://doi.org/ 10.1007/s11240-018-1477-7

Jaramillo, De EH, Forero A, Cancino G, Moreno AM, Monsalve LE and Acero W (2008) In vitro regeneration of three chrysanthemum (Dendrathema grandiflora) varieties via organogenesis and somatic embryogenesis. Universitas Scientiarum. 13(2): 118-127.

Kazeroonian R, Mousavi A, Kalate Jari S and Tohidfar M (2018) Factors Influencing in vitro organogenesis of Chrysanthemum morifolium cv. 'Resomee Splendid.' Iranian Journal of Biotechnology. 16(2): 132-139. https://doi.org/10.21859/1jb.1454

Lee T, Huang MEE and Pua EC (1997) High frequency shoot regeneration from leaf disc explants of garland chrysanthemum (Chrysanthemum coronarium L.) in vitro. Plant Science. 126(2): 219226. https://doi.org/10.1016/S0168-9452(97)00098-8

Lema-Rumińska J and Mellem A (2017) Genetic diversity of chrysanthemum plants derived via somatic embryogenesis using rapd markers. Acta Scientiarum Polonorum, Hortorum Cultus. 16(6): 149-156. https://doi.org/10.24326/asphc.2017.6.13

Lim KB, Kwon SJ, Lee SI, Hwang YJ and Naing AH (2012) Influence of genotype, explant source, and gelling agent on in vitro shoot regeneration of chrysanthemum. Horticult. Environ. Biotechnol. 53(4): 329-335. https://doi.org/10.1007/s13580-012-0063-x 
In vitro Regeneration Protocol for Chrysanthemum

Miler N and Jędrzejczyk I (2018) Chrysanthemum plants regenerated from ovaries: A study on genetic and phenotypic variation. Turkish J. Bot. 42(3): 289-297. https://doi. org/10.3906/bot$1707-19$

Miler N and Kulus D (2018) Microwave treatment can induce chrysanthemum phenotypic and genetic changes. Scientia Horticult. 227(1): 223-233. https://doi.org/10.1016/.scienta. 2017.09.047

Miler N and Malgorzata Z (2014) Somaclonal variation of Chrysanthemum propagated in vitro from different explant types. Acta Sci. Pol. Hortorum Cultus. 13(2): 69-82.

Naing AH, Jeon SM, Han JS, Lim SH, Lim KB and Kim CK (2014) Factors influencing in vitro shoot regeneration from leaf segments of Chrysanthemum. Comptes Rendus - Biologies. 337(6): 383-390. https://doi.org/10.1016/.crvi.2014.03.005

Nasri F, Zakizadeh H, Vafaee $Y$ and Mozafari AA (2018) Callus Induction and Plant Regeneration of Chrysanthemum morifolium and C. coccineum via Direct and Indirect Organogenesis and Genetic Fidelity Analysis Using IRAP, ISSR and SCoT Molecular Markers. J. Ornamen. Plants. 8(4): 265-284. http://jornamental.iaurasht.ac.ir/article_545325.html

Samala S, Kongton K, Saisaard K, Nupan B, Thongyai K and Taweerodjanakarn S (2017) Effects of plant growth regulators on multiple shoots regeneration of in vitro Chrysanthemum morifolium Ramat. Acta Hortic. 1167(1): 143-148. https://doi.org/10.17660/ActaHortic. 2017. 1167.22

Sarker RH and Ismat S (2001) In vitro propagation of Chrysanthemum (Chrysanthemum morifolium Ramat) through callus culture. Plant Tissue Cult. and Biotechnol. 11(1): 85-91.

Teixeira da Silva JA, Lema-Rumińska J, Tymoszuk A and Kulpa D (2015) Regeneration from chrysanthemum flowers: a review. Acta Physiologiae Plantarum 37(2): 36. https://doi. org/10. 1007/s11738-015-1773-3

Tymoszuk A and Kulus D (2020) Silver nanoparticles induce genetic, biochemical, and phenotype variation in chrysanthemum. Plant Cell, Tissue and Organ Cult. 143: 331-344. https://doi. org/10.1007/s11240-020-01920-4

Waseem K, Jilani MS, Khan MS, Kiran M and Khan G (2011) Efficient in vitro regeneration of chrysanthemum (Chrysanthemum morifolium L.) plantlets from nodal segments. African J. Biotechnol. 10(8): 1477-1484. https://doi.org/10.5897/AJB09.1820

Xu P, Zhang Z and Wang B (2012) Somatic embryogenesis and plant regeneration in chrysanthemum (Yuukou). Plant Cell Tiss. Organ Cult. 111: 393-397. https://doi.org/10.1007/ s11240-012-0201-2

Yesmin S, Das K, Hashem A and Hasan MS (2014) Efficient in vitro Regeneration of Chrysanthemum (Chrysanthemum morifolium Ramat.) Through Nodal Explant Culture. Nuclear Science and Applications. 23(1\&2): 47-50. https://doi.org/10.13140/RG.2.2. 15980.67208

Zalewska M, Tymoszuk A and Miler N (2011) New chrysanthemum cultivars as a result of in vitro mutagenesis with the application of different explant types. Acta Scientiarum Polonorum, Hortorum Cultus. 10(2): 109-123. 